\title{
Propuestas de Juana Manrique de Lara a la política bibliotecaria de Vasconcelos
}

\author{
Martha Alicia Añorve Guillén *
}

Artículo recibido:

21 de junio de 2005.

Artículo aceptado:

22 de junio de 2005.

\section{RESUMEN}

Este artículo presenta las aportaciones que Juana Manrique de Lara (primera bibliotecaria mexicana formada tanto en la primera Escuela Nacional de Bibliotecarios y Arcbiveros que se fundó en México en 1916 como en la Library School of the New York Public Library) hizo a la política bibliotecaria inspirada por el intelectual mexicano y fundador de la Secretaría de Educación Pública, José Vasconcelos, en el periodo de 1921 a 1924.

De acuerdo con las circunstancias de la vida profesional de Manrique de Lara sus aportaciones se presentan agrupadas en tres periodos: a) las que presentó por medio de artículos publicados en Biblios, boletín de la Biblioteca Nacional de México, entre octubre de 1921 a febrero de 1922, fechas en que desde su lugar de bibliotecaria técnica de dicha Biblioteca seguía el

* Centro Universitario de Investigaciones Bibliotecológicas de la UNAM, México. anorve@servidor.unam.mx

INVESTIGACIÓN BIBLIOTECOLÓGICA, Vol. 20, Núm. 41, julio/diciembre, 2006, México, ISSN: 0187-358X. pp. 63-90 
movimiento bibliotecario emprendido por el Departamento de Bibliotecas de la recién fundada Secretaría de Educación Pública (SEP); b) las acciones que ya como encargada de la Biblioteca "Amado Nervo" (una de las primeras bibliotecas públicas que abrió el Departamento de Bibliotecas de la SEP) emprendió a favor de la lectura y del uso de la biblioteca en una comunidad popular de la ciudad de México entre marzo de 1922 y febrero de 1923 , y c) las propuestas e ideas que presentó por escrito al Departamento de Bibliotecas de la SEP desde su estancia de estudio en Nueva York, y las acciones que ya como inspectora de bibliotecas del mencionado Departamento pudo emprender a su regreso de Estados Unidos. El conjunto de estas últimas propuestas, ideas y acciones las presentó entre 1923 y 1924.

Palabras clave: Política bibliotecaria; Bibliotecas públicas; Manrique de Lara.

\section{ABSTRACT \\ Juana Manrique de Lara's proposals to Vasconcelos's library science policy Martha Alicia Añorve-Guillén}

This article analyses the contributions (1921-1924) made by Juana Manrique de Lara, Mexico's first librarian, to the library science policy inspired by José Vasconcelos, Mexican intellectual founder of the Secretaría de Educación Pública (Public Education Ministry). Manrique de Lara's contributions are grouped in three periods: a) papers published in Biblios, bulletin of the Biblioteca Nacional de México (Mexican National Library's Bulletin between October 1921 and February 1922); b) actions to promote reading and the use of the library in a working class community of Mexico City, while head of Public Library "Amado Nervo", and c) proposals and ideas she presented to the Departamento de Bibliotecas de la SEP (Library Department of SEP's) when she was still studying in New York, and those she made on her return as the library inspector of the said Department (mainly during 1923,24).

Keywords: Library policy; Public libraries; Manrique de Lara. 


\section{INTRODUCCIÓN}

— 1 presente artículo está destinado a poner de manifiesto las aportaciones Eque Juana Manrique de Lara -una de las primeras bibliotecarias formadas tanto en México en la primera Escuela Nacional de Bibliotecarios y Archiveros que se fundó en este país en 1916 como en The Library School of the New York Public Library en donde realizó estudios entre 1923 y 1924-, hizo a la política bibliotecaria mexicana inspirada por el intelectual José Vasconcelos.

El estudio de las aportaciones de Juana Manrique de Lara a la política bibliotecaria de Vasconcelos permite no sólo identificar y valorar las propuestas que hizo dicha bibliotecaria a la política bibliotecaria de uno de los más importantes periodos de la bibliotecología mexicana del siglo $\mathrm{XX},{ }^{1}$ sino comprender y quizá generalizar que los bibliotecarios y bibliógrafos que colaboraron en dicho periodo no fueron simples operarios del pensamiento bibliotecario vasconcelista y, permite añadir también que el pensamiento bibliotecario del régimen carrancista ${ }^{2}$ permeó al periodo de Vasconcelos a través de los bibliógrafos y de los primeros bibliotecarios que se formaron en la escuela de 1916, y que continuaron trabajando para el desarrollo bibliotecario emprendido por Vasconcelos.

La contribución de los bibliotecarios al periodo de Vasconcelos no ha sido objeto de atención particular, ni tampoco lo ha sido el reconocimiento de alguna línea de continuidad del pensamiento bibliotecario durante el periodo del carrancismo - que es ante todo un planteamiento surgido de las aspiraciones de la revolución, como también lo es el de Vasconcelos-. Esta línea de continuidad tampoco fue reconocida en su momento debido a la enemistad política existente entre Vasconcelos y Carranza.

No obstante que como telón de fondo del estudio de las aportaciones de Juana Manrique de Lara se encuentran tanto las intenciones de poner de manifiesto, aunque fuera a través de un solo bibliotecario, las aportaciones de

1 Linda Sametz de Walerstein, Vasconcelos el hombre del libro: la época de oro de las bibliotecas. México, D.F.: Instituto de Investigaciones Bibliográficas, UNAM, 1991, 227 p. Esta autora reconoce este periodo como la "época de oro de las bibliotecas".

2 Cuando hablamos del régimen carrancista nos referimos al liderazgo ostentado por Venustiano Carranza entre febrero de 1913 y mayo de 1920, en él se distinguen cuatro periodos: 1.) Febrero de 1913 al 13 de agosto de 1914, campaña militar contra el huertismo hasta la ocupación de la ciudad de México. 2.) Del 20 de agosto de 1914 al 14 de abril de 1916, periodo que abarca desde el momento en que Carranza se ocupó del Poder Ejecutivo de la Unión, conservando el nombramiento de Primer Jefe del Ejército Constitucionalista, hasta que vuelve a la capital una vez vencidas las fuerzas de la Convención y de la División del Norte y obtiene el reconocimiento de los Estados Unidos. 3.) De la fecha anterior al $1^{\circ}$ de mayo de 1917, en que asume la Presidencia de nuestro país a partir de las elecciones convocadas de acuerdo con la nueva Constitución Política del 5 de febrero de 1917. 4.) Desde que el gobierno constitucionalista, asume la presidencia en la fecha anteriormente citada, hasta el 21 de mayo de 1920, en que Carranza fue asesinado en Tlaxcalantongo, estado de Puebla. 
los bibliotecarios a la política bibliotecaria de Vasconcelos, como identificar los ideales bibliotecarios manifestados ya en el periodo que le antecedió, el análisis de las aportaciones de Manrique de Lara permite además de recoger lo anterior, analizar, a través de ella, la influencia que tuvo de la biblioteconomía estadounidense en la bibliotecología mexicana de esa época. Esto porque ella recibió la influencia de ese modelo tanto de manera indirecta -este modelo inspiró la acción bibliotecaria del carrancismo en el que ella se formó y para el que trabajó- como de forma directa al haber estudiado biblioteconomía en Nueva York, mientras que simultáneamente hacía sugerencias para desarrollar el sistema bibliotecario mexicano.

Por otra parte una revisión rápida de los artículos que a Manrique de Lara se le publicaran en el periodo de 1921 a 1924, nos decidió a remitir la investigación hacia el análisis de la totalidad de sus aportaciones a la política bibliotecaria inspirada por Vasconcelos.

Por todo lo anterior, más la importancia que reviste el periodo vasconcelista en la vida cultural y educativa de nuestro país, decidimos estudiar el total de las aportaciones de la bibliotecaria Manrique de Lara durante tan importante periodo bibliotecario.

La decisión de estudiar las aportaciones de Juana Manrique de Lara a la política bibliotecaria de Vasconcelos se fue reafirmando cuando encontramos indicios de aportaciones de esta biblioteca desde sus primeros artículos publicados entre 1921 y $1922,{ }^{3}$ así como en otro documento publicado ya desde su estancia en Nueva York, titulado "Proyectos de reformas e introducción de sistemas de biblioteconomía, según los métodos norteamericanos, en las bibliotecas de la república mexicana". ${ }^{4}$ De entrada este sólo título sugería otra posible fuente de aportaciones de Manrique de Lara al desarrollo bibliotecario emprendido por Vasconcelos, planteadas en ese momento bajo el influjo directo que en ella ejercía la biblioteconomía norteamericana.

Así, el objetivo específico de la investigación de la que dimanan las aportaciones que presentamos en este artículo fue dilucidar las aportaciones de Juana Manrique de Lara a la política bibliotecaria inspirada por José Vasconcelos.

Para alcanzar este objetivo decidimos ubicar y valorar en contextos pertinentes las acciones, los proyectos y los artículos llevadas a efecto por esta bibliotecaria entre 1921-1924.

3 Juana Manrique de Lara. "La biblioteca pública y los alumnos de las escuelas preparatorias", en Biblos, III, 145 (29 octubre, 1921), p. 175.

-Manrique de Lara. "Las Bibliotecas Públicas y los alumnos de las escuelas primarias", en Biblos, III, 146 ( 5 noviembre, 1921), p. 179.

-Manrique de Lara. "Las bibliotecas infantiles y juveniles", en Biblos, IV, 158, 159 (28 enero, 4 febrero, 1922), pp. 15; 18-19.

4 Manrique de Lara. "Proyectos de reformas e introducción de sistemas de biblioteconomía, según los métodos norteamericanos, en las bibliotecas de la República Mexicana”, en El libro y el pueblo, III, 7-9 (julio-septiembre, 1924), pp. 173-175. 
Es conveniente añadir que en el transcurso de la investigación nos atrevimos también a formular algunas hipótesis relacionadas con el presente del desarrollo bibliotecario mexicano. Esto lo decidimos cuando tomamos conciencia de que algunas de las propuestas hechas por Manrique de Lara desde los años veinte, podrían todavía tener vigencia y contribuir a resolver problemas actuales.

Dilucidar las propuestas de Juana Manrique de Lara demandaba, en primer lugar, analizar sus propuestas, artículos y acciones a la luz de las medidas emprendidas en aquellos momentos por el Departamento de Bibliotecas de la SEP, más lo dispuesto en materia de bibliotecas por el Reglamento de dicha Secretaría, ${ }^{5}$ y estudiar el reglamento que éste emitiera para bibliotecas públicas, ${ }^{6}$ así como también los contextos en que Manrique de Lara se formó tanto en la primera escuela de bibliotecarios en México como en Nueva York, aunque también había que tomar en cuenta el marco de su vida familiar y escolar anterior que transcurrió en escuelas de la Iglesia metodista.

Conscientes de nuestro compromiso con la bibliotecología y de que en nuestra investigación buscábamos dilucidar nada menos que las aportaciones de una bibliotecaria en el momento cumbre del desarrollo de las bibliotecas populares en nuestro país, y de que nos disponíamos a hacerlo sin pretender restar o minimizar la amplia visión bibliotecaria de Vasconcelos, procuramos salvaguardar en lo posible, por la vía del método y de las fuentes, la objetividad de los encuentros de nuestra investigación.

Así por ejemplo las primeras propuestas de Manrique de Lara (que están dirigidas a argumentar ante la SEP la necesidad de fundar paralelamente a las bibliotecas públicas, las infantiles y juveniles que el país necesitaba) se fueron intercalando y comparando, en la línea del tiempo, con los testimonios de las acciones que al respecto se tomaban en el Departamento de Bibliotecas.

Esta forma de trabajo nos permitió ubicar que en el momento en que Manrique de Lara levantaba su voz a favor de este tipo de servicios bibliotecarios, el Departamento de Bibliotecas no fundaba aún ninguna biblioteca infantil y tampoco había creado en las bibliotecas públicas secciones especiales para niños y jóvenes, ni había publicado la selección de obras para bibliotecas infantiles. ${ }^{7}$

En cuanto a las aportaciones hechas entre 1923 y 1924, en cuya valoración se atiende también el principio metodológico ya explicado, tratamos en principio de considerar como tales únicamente aquéllas hechas por Juana que no estaban siendo ya realizadas por el Departamento de Bibliotecas de la

5 "Reglamento de la Secretaría de Educación Pública Federal", en Boletín de la Secretaría de Educación Pública, I, 2 (septiembre, 1922), pp. 32-75.

6 "Reglamento de Bibliotecas Públicas" en El libro y el pueblo, I, 4 (junio, 1922), p. 26.

7 “Tipos de bibliotecas", en Boletín de la Secretaría de Educación Pública, I, 1, (1'. Mayo, 1922, pp. 295-298. 
SEP. Las que ya se estaban atendiendo quedaron fuera, como fue el caso, por ejemplo, del préstamo a domicilio.

\section{Aportaciones en su contexto}

Encontramos que las aportaciones que Juana Manrique de Lara hizo a la política bibliotecaria del Departamento de Bibliotecas fueron presentadas en los siguientes momentos:

I. Octubre de 1921 a febrero de 1922

II. Marzo de 1922 a febrero de 1923

III. Febrero de 1923 a diciembre de 1924

No obstante que en los periodos señalados en los puntos I y II se analizan tanto las propuestas de la autora, como las acciones llevadas a efecto por ella o por el Departamento de Bibliotecas, y las influencias que le permitieron a Juana hacer sus propuestas o realizar determinadas acciones, en el periodo a que remite el punto III destacamos solamente sus acciones en la biblioteca pública "Amado Nervo" relacionándolas con la preparación recibida (influencias) que le permitió llevarlas a efecto.

\section{Octubre de 1921 a febrero de 1922}

En este periodo, Manrique de Lara -quien años atrás había trabajado en favor de la organización de la proyectada Biblioteca Infantil que la Biblioteca Nacional estuvo a punto de abrir en 1917- se desempeñaba en la Biblioteca Nacional como catalogadora. Desde ahí presentó a la SEP sus planteamientos sobre la urgente necesidad de abrir bibliotecas infantiles y juveniles argumentando que este tipo de bibliotecas eran piezas fundamentales para mejorar la educación escolar, para formar tanto el gusto lector como para introducir en el aprendizaje el uso de la biblioteca desde temprana edad.

Las aportaciones de este periodo las derivé del análisis de los artículos siguientes: "Las bibliotecas públicas y los alumnos de las escuelas preparatorias", "Las bibliotecas públicas y los alumnos de las escuelas primarias" y "Las bibliotecas infantiles y juveniles". ${ }^{10}$ Los indicios de aportaciones encontrados en estos artículos fueron analizados en los contextos relativos tanto a 
las influencias que Manrique de Lara recibiera de la Escuela Nacional de Bibliotecarios y Archiveros como a las que recibiera en el desarrollo bibliotecario emprendido por el Departamento de Bibliotecas de la SEP en aquellos precisos momentos.

\section{Aportaciones}

Ante: a) la ausencia de servicios bibliotecarios para niños y jóvenes, b) la falta de tradición lectora entre la población adulta, c) la escasa y pobre calidad de lecturas entre las clases populares, d) las deficiencias de la escuela en la formación cognoscitiva, moral y estética, y e) la necesidad de formar a los niños y jóvenes tanto en el hábito lector como en el uso de la biblioteca, y de conducir al niño hacia una lectura de calidad, Juana Manrique de Lara hizo a la Secretaría de Educación Pública las siguientes sugerencias y aportaciones:

1. Fundar bibliotecas para niños y jóvenes o al menos crear, en las bibliotecas públicas que se fundaban, secciones especiales para atender a esta población.

2. Reformar los horarios escolares para favorecer la asistencia de los niños a la biblioteca.

3. Acudir a estrategias pedagógicas que favorecieran el uso de la biblioteca (ella sugirió algunas).

4. Señalar (con fundamentos) la necesidad de que el bibliotecario y el maestro trabajaran juntos guiando las lecturas de niños y jóvenes. Consideraba que el bibliotecario y el maestro "deberán ser siempre colaboradores mutuos en la magna obra de la educación patria" ${ }^{11}$

5. Ofrecer por primera vez, en el México emanado de la revolución, un perfil ideal del bibliotecario infantil; así, señaló:

[...] debe ser un educador, un maestro y un colaborador efectivo y valioso de los maestros de las escuelas, además, un amigo cariñoso e inteligente de los niños y jóvenes que concurran al establecimiento, a los cuales ayudará con sus consejos y guiará en la formación de sus gustos literarios y en la selección de obras de buenos autores. Para tener todas estas cualidades será necesario que posea una vasta cultura general, un conocimiento extenso de la pedagogía y psicología infantiles, aparte de los conocimientos especiales que su carrera requiere. Cualidades difíciles, pero indispensables si se desea un buen bibliotecario de niños. ${ }^{12}$

11 Manrique de Lara, Juana. "Las bibliotecas públicas y los alumnos de las escuelas primarias”, ..., p. 179.

12 Manrique de Lara, "Las bibliotecas infantiles y juveniles", ..., p. 18 
Más tarde, ya desde Estados Unidos, añadió:

[...] su especialización requiere el título de maestros o una práctica de dos o tres años en las escuelas primarias, aparte de los conocimientos técnicos de la profesión, [...]. ${ }^{13}$

6. Presentarle a la Secretaría un proyecto modelo para el establecimiento de una biblioteca infantil mexicana, en el que acotaba lo relativo a los siguientes elementos: el local, el mobiliario, el bibliotecario, los libros, los lectores, la catalogación y clasificación, el horario de la biblioteca y la hora del cuento.

7. Pedirle a la SEP que se ocupara de la selección de libros para niños. Para ello le ofreció criterios de selección que ella misma había aplicado cuando elaboró la que tal vez haya sido la primera lista del México revolucionario: 300 obras en español para niños y jóvenes, que formarían parte de la colección de la proyectada biblioteca infantil que planteara Loera y Chávez y que más tarde insistieran en abrir las autoridades de la Biblioteca Nacional, también durante el régimen de Carranza.

\section{Acciones}

Aunque nunca se les dio un reconocimiento abierto a las aportaciones de Manrique de Lara, seguramente porque coincidían con las intenciones de Vasconcelos, observamos que algunas de las ideas manifestadas por Manrique de Lara con relación a la biblioteca infantil se atendieron durante el correspondiente periodo de la siguiente manera:

1. En el Reglamento de Bibliotecas Públicas de la SEP publicado en junio de 1922 quedó manifestada de alguna manera la relación entre la biblioteca y la escuela, que Manrique de Lara también expresara, cuando en dicho Reglamento se asentó como obligación de este tipo de bibliotecarios la de:

Hacer una propaganda real y efectiva para lograr el aumento de lectores en la Biblioteca, en las fábricas, talleres y escuelas del lugar, así como la que ya hemos señalado en este artículo en relación a pedir a los directores de las Escuelas que lleven a los alumnos a las salas de lectura para acostumbrarlos a frecuentar las bibliotecas. ${ }^{14}$ 
2. Para finales de 1922, en la Conferencia que Vasconcelos impartió en el Continental Memorial Hall de Washington, señaló que las bibliotecas populares contaban con una colección especial de libros infantiles, ${ }^{15}$ colección que se dio a conocer en mayo de 1922 . $^{16}$

3. La fundación de secciones para niños en las bibliotecas públicas que también fuera planteada por Manrique de Lara ante la ausencia generalizada de bibliotecas infantiles en el país, se atendió en septiembre de 1923. El Departamento de Bibliotecas señaló: "se ha resuelto que toda biblioteca que se funde tenga un anexo infantil". ${ }^{17}$

4. Coincidiendo con el modelo de biblioteca infantil (evidentemente un modelo lógico universal) planteado por Manrique de Lara en 1922, la SEP funda, a finales de 1923, su primera biblioteca infantil, que quedó anexa a la Biblioteca "Modelo". ${ }^{18}$ Desafortunadamente la fundación de este tipo de bibliotecas no fue una acción sistemática ni se generalizó en el país.

5. En relación con la hora del cuento, propuesta por Manrique de Lara como una medida para fomentar el gusto lector, suponemos que se puso en práctica ya desde la Biblioteca Infantil anexa a la de la SEP.

6. Por último y en relación con la difusión de obras para niños, aunque esta no fue una acción que Manrique de Lara haya sugerido de manera explícita, mencionamos que fue atendida de manera más concreta con la publicación en 1924 de la obra Lecturas clásicas para niños. ${ }^{19}$

Como para el momento en que Manrique de Lara proponía las acciones que se mencionaron en el rubro anterior denominado Aportaciones, la SEP aún no las ponía en práctica, podemos concluir que desde la profesión bibliotecaria, y a través de Manrique de Lara, se levantó una voz que les planteaba a las autoridades responsables de la política bibliotecaria de los años veinte, la necesidad básica de fundar servicios bibliotecarios para niños y jóvenes, como la forma idónea para cimentar el gusto lector y el uso de la biblioteca a lo largo de toda la vida, y como un contribuyente importante para elevar el nivel educativo del pueblo mexicano.

Como hipótesis consideramos hoy que de haberse seguido la recomendación de Manrique de Lara de atender con servicios bibliotecario ad boc a

15 José Vasconcelos, “Conferencia leída en el 'Continental Memorial Hall' de Washington”, en Boletín de la Secretaría de Educación Pública, I, 3 (enero, 1923), pp. 5-16.

16 "Tipos de bibliotecas", ..., pp. 295-298.

17 "Las bibliotecas públicas en México", en El libro y el pueblo, II, 6-7 (agosto-septiembre, 1923), p. 138.

18 "La biblioteca infantil", en El libro y el pueblo, II, 8-10 (octubre-diciembre, 1923), p. 202.

19 Lecturas clásicas para niños. México: Departamento Editorial, SEP, 1981. 2 vols. 
niños y jóvenes desde los años de la Revolución, México contaría hoy con un mayor porcentaje de la población que hubiese desarrollado el hábito de la lectura y el uso de la biblioteca, y que esto contribuiría a lograr una sociedad más equitativa y de mayor competencia en el concierto internacional.

Por otra parte nos parece que debido, precisamente, a la falta de una continuidad sistemática y generalizada en México en las acciones bibliotecarias y escolares, para fomentar el gusto lector desde la más tierna infancia, los planteamientos que Manrique de Lara hiciera sobre la necesidad de implantar servicios bibliotecarios para la población infantil y juvenil mexicana siguen siendo, en su esencia, vigentes.

\section{Influencias}

Entre las influencias que pudieran subyacer a las aportaciones que Manrique de Lara le hiciera a Vasconcelos entre 1921 y 1922, y que estuvieron dirigidas a la implantación de bibliotecas infantiles o de secciones para este sector de la población en las bibliotecas públicas que se fundaban -como el medio idóneo para cimentar el gusto lector y el uso de la biblioteca desde temprana edad-nosotros encontramos las siguientes:

La literatura internacional sobre este tema. Esta afirmación se basa en las alusiones que en sus artículos dirigidos a la SEP hace Manrique de Lara acerca de la realidad en las bibliotecas infantiles de otros países.

Las ideas expresadas en torno a la biblioteca como un sistema educativo y las medidas tomadas en el régimen carrancista. El exponente principal de estas ideas fue el profesor Agustín Loera y Chávez; promotor del movimiento bibliotecario del carrancismo. Desde 1915, este personaje, en su calidad de Subdirector de la Biblioteca Nacional, le propuso al Subsecretario de Instrucción Pública y Bellas Artes que se incluyera entre los temas de estudio de los viajes culturales de los profesores mexicanos a los Estados Unidos “[...] uno en especial que se refiere a bibliotecas infantiles [...]". ${ }^{20}$ En paralelo, en diciembre de 1915 se decretaba la institución de bibliotecas infantiles en las escuelas primarias superiores. ${ }^{21}$ Asimismo encontramos que en 1916, Loera y Chávez expresaba el siguiente ideal: “[...] ver realizado el anhelo de establecer en cada barrio de la ciudad, la Biblioteca circulante infantil, que proporcionará a cada niño el libro que necesita [...]";22 Loera y Chávez también luchó por

20 AHBN, Fondo Administrativo. Carpeta 70. Exp. 1558. No. 2515. [Oficio turnado por Agustín Loera y Chávez, Subdirector de la Biblioteca Nacional, al Subsecretario de Instrucción Pública y Bellas Artes, 21 de Septiembre de 1915].

21 AHBN, Fondo Administrativo. Carpeta 70. Exp. 1559. No. 2516. [Decreto de institución de bibliotecas infantiles en las Escuelas Primarias Superiores. 20 de noviembre de 1915]. 
el establecimiento de una biblioteca infantil en la Biblioteca Nacional e incluso porque el uso de la biblioteca y el libro se generalizara en todos los niveles de enseñanza por lo que propuso al ya citado ministerio de educación incluir en los programas de Lengua Nacional de las escuelas primarias, secundarias, normales preparatorias e industriales, el tema sobre el manejo de libros y el de las bibliotecas "[...] iniciando un adelanto que principia con el conocimiento del alfabeto y tiene por coronamiento la cultura superior del esteta o del pensador". ${ }^{23}$

Consideramos que las ideas expresadas por este personaje eran compartidas en general por los profesores de la escuela de bibliotecarios de la cual él era director, y tanto éstos como las acciones que en aquel momento se tomaban influyeron en la perspectiva de Manrique de Lara sobre la urgencia de cimentar desde temprana edad el gusto por la lectura y por el uso de la biblioteca.

Especialmente en las clases de Nicolás León se revisaron no sólo la importancia de la biblioteca dentro de "un sistema liberal de educación" y su equiparación "con una buena escuela", sino las tres finalidades principales de las bibliotecas: los elementos que se debían considerar en su diseño y la definición e importancia de las bibliotecas infantiles, el tipo de libros para éstas, y la hora del cuento. ${ }^{24}$

Por último cabe señalar que es para nosotros evidente que al ser la propia Manrique de Lara nombrada como jefa de la Biblioteca Infantil ${ }^{25}$ que pretendía fundar la Biblioteca Nacional, ya estaba plenamente convencida de la importancia que tenía este tipo de bibliotecas, y sus correspondientes colecciones.

Por todo lo anterior nos parece que en la genuina expresión que hace Manrique de Lara a la SEP sobre la necesidad de contar con bibliotecas para niños y jóvenes, subyace el legado de la época de Carranza transmitido por la Escuela Nacional de Bibliotecarios y Archiveros, y su vivencia laboral en el principal centro bibliotecario de aquel momento: la Biblioteca Nacional y, especialmente, su experiencia como organizadora de aquella pretendida Biblioteca Infantil.

\section{Marzo de 1922 a febrero de 1923}

En este periodo la bibliotecaria Juana se había integrado al Departamento de Bibliotecas de la recién fundada SEP con la responsabilidad de dirigir la bi-

23 AHBN, Fondo de la Escuela Nacional de Bibliotecarios y Archivistas Carpeta 114. Exp. 3360. No. 4354. [Sugerencia del Director de la Escuela Nacional de Bibliotecarios y Archivistas al Ministro de Educación, de incluir en los programas de Lengua Nacional el tema de manejo de bibliotecas y uso, selección y prácticas de asimilación de libros. 20 de abril de 1916].

24 Nicolás León Calderón. Biblioteconomía: notas de las lecciones orales del Profesor Dr. Nicolás León en la Escuela Nacional de Bibliotecarios y Archiveros. México: Antigua Imprenta de Murguía, 1918. vii, 167 p.

25 AHBN, Fondo Administrativo. Carpeta 77. Exp. 1908. No. 2870. [Relación de oficios emitidos por la Biblioteca Nacional durante el año de 1917]. 
blioteca popular "Amado Nervo". Gracias a su vocación y preparación bibliotecaria (en la que desde nuestro punto de vista se incluyeron no únicamente bases cognoscitivas sino también actitudes favorables hacia la importancia de la lectura y de la biblioteca en la vida del mexicano), Manrique de Lara pudo apoyar a través de su acción el ideal que compartía con Vasconcelos de fomentar la lectura, el uso de la biblioteca e incluso la alfabetización entre las clases menos favorecidas.

\section{Acciones de Juana Manrique de Lara en la Biblioteca "Amado Nervo"}

1. Dio cabal cumplimiento a las aspiraciones vanconcelistas tanto de "llevar a cabo o dirigir las labores de catalogación", como de "hacer una propaganda real y efectiva para lograr el aumento de lectores, en las fábricas, talleres y escuelas del lugar", esto último no obstante que el radio de acción de su biblioteca abarcara una "zona roja". ${ }^{26} \mathrm{Ocu}-$ parse del proceso que va desde la catalogación hasta la difusión es algo que Manrique de Lara pudo lograr gracias a su preparación bibliotecaria y a que compartía con Vasconcelos la convicción de llevarle la lectura al pueblo.

2. Logró colocar a la Biblioteca "Amado Nervo" como la primera en asistencia de lectores al ser una de las bibliotecas mejor organizadas y administradas, ${ }^{27}$ y cumplió también ampliamente con el precepto de visitar a la comunidad para estimular en sus habitantes la lectura, el aprendizaje de la lecto-escritura y el uso de la biblioteca.

3. Formuló el reglamento interno de dicha biblioteca y la convirtió en la primera biblioteca pública del México posrevolucionario que fijara por escrito los derechos y obligaciones de los lectores. Nuevamente su formación de bibliotecaria adquirida en la primera Escuela Nacional de Bibliotecarios y Archiveros le permitía no sólo hacer esto sino también comprender su relevancia. La publicación de dicho reglamento en El Libro y el Pueblo bajo el título "Proyecto de reglamento interior para uso de la Biblioteca Pública 'Amado Nervo", ${ }^{28}$ demuestra la importancia que el Departamento de Bibliotecas le dio a esta iniciativa.

26 Estela Morales Campos, "Entrevista: Juana Manrique de Lara”, Investigación bibliotecológica, I, 1 (agosto, 1986) pp. 8-23.

27 "Informe rendido por la inspección del Departamento de Bibliotecas acerca del funcionamiento de las bibliotecas públicas fundadas en la ciudad de México y en algunas poblaciones del Distrito Federal", en Boletín de la Secretaría de Educación Pública, I, 3 (enero, 1923), pp. 323-325.

28 Manrique de Lara. "Proyecto de reglamento interior para uso de la biblioteca Amado Nervo", en El libro y el pueblo, I, 12 (febrero, 1923), p. 203. 
Estas acciones son para nosotros una muestra objetiva de la importancia que tiene el hecho de que el bibliotecario reúna el cuatrinomio: vocación (que por cierto Manrique de Lara parece haber descubierto a partir del contacto con su formación de bibliotecaria); sólida preparación formal en biblioteconomía; toma de conciencia; y actitud favorable y de compromiso para hacer operativo el principio de importancia de la lectura, la información y el uso de la biblioteca en la conformación de una verdadera sociedad.

La actitud de servicio manifestada por Manrique de Lara a lo largo de su vida profesional y demostrada de forma tan clara en el tiempo que se desempeñó en la "Amado Nervo" es una disposición que no debemos dejar de inculcar en los bibliotecarios mexicanos de los años presentes.

La notoria concurrencia de lectores a la biblioteca administrada por Juana Manrique de Lara le mereció que la SEP le otorgara una comisión para realizar estudios de biblioteconomía en una de las mejores escuelas de bibliotecarios de los Estados Unidos.

\section{Febrero de 1923 a diciembre de 1924}

De este periodo se analizaron tanto las aportaciones de Manrique de Lara desde su estancia de estudios en los Estados Unidos, como las acciones que realiza a su regreso a México a mediados de 1924 y al reincorporarse al Departamento de Bibliotecas ya como inspectora de bibliotecas de dicho Departamento. El análisis termina al finalizar la administración del presidente Álvaro Obregón.

La experiencia del desarrollo bibliotecario estadounidense y la preparación bibliotecaria que Manrique de Lara adquiriera en ese país, sumada a su ya arraigado compromiso social y profesional, la llevarían a proponer, mientras cubría su estancia de estudios en Nueva York, proyectos para el mejoramiento integral del sistema bibliotecario mexicano, a escribir sobre temas biblioteconómicos para favorecer la actitud, la preparación y la actuación de los bibliotecarios mexicanos, y a pugnar tanto para que la formación del bibliotecario mexicano fuera más completa e impartida de manera formal por la escuela correspondiente, como para colocar la formación de bibliotecarios como pieza clave del proyecto bibliotecario mexicano.

Para analizar las aportaciones que Manrique de Lara efectuara desde los Estados Unidos se revisaron los documentos que desde allá enviara tanto a la luz del desarrollo bibliotecario mexicano como del norteamericano, que era en ese momento su referente.

Los documentos escritos por Manrique de Lara desde los Estados Unidos y enviados al país, en torno a los cuales versó el análisis son los siguientes: 
"La Biblioteca Pública de Nueva York: Informe al Departamento de Bibliotecas", ${ }^{29} \mathrm{el}$

Informe que la señorita Juana Manrique de Lara, oficial bibliotecario, presenta al ciudadano Jefe del Departamento de Bibliotecas, relativo a sus estudios en Estados Unidos: La Escuela de Bibliotecarios de la Biblioteca Pública de Nueva York y requisitos para ingresar a ella; ${ }^{30}$

"La clasificación y la catalogación de las bibliotecas públicas de Nueva York"; 31 "La organización de bibliotecas públicas en la ciudad de Nueva York"; ${ }^{32}$ el "Programa de la Escuela de Bibliotecarios anexa a la Biblioteca Pública de la ciudad de Nueva York";3 "Bibliotecas y bibliotecarios"; 34 las "Anotaciones y revistas de libros"; 35 el

Informe y sugestiones que rinde la señorita Juana Manrique de Lara al Jefe del Departamento de Bibliotecas, como resultado de sus estudios especiales de Biblioteconomía en la ciudad de Nueva York; ${ }^{36}$

los "Proyectos de reformas e introducción de sistemas de biblioteconomía, según los métodos norteamericanos, en las bibliotecas de la República Mexicana"; 37 el "Plan de un boletín para una biblioteca de la ciudad de México"; 38 y "La selección de libros para las diferentes clases de bibliotecas y en especial para las bibliotecas públicas" ${ }^{39}$

29 Manrique de Lara. "La Biblioteca Pública de Nueva York: Informe al Departamento de Bibliotecas", en El libro y el pueblo, II, 2-3 (abril-mayo, 1923), p. 35.

30 Manrique de Lara. "Informe que la señorita Juana Manrique de Lara, oficial bibliotecario, presenta al ciudadano Jefe del Departamento de Bibliotecas, relativo a sus estudios en Estados Unidos: La Escuela de Bibliotecarios de la Biblioteca Pública de Nueva York y requisitos para ingresar a ella", en Boletín de la Secretaría de Educación Pública I, 4 (enero-junio, 1923), p. 298.

31 Manrique de Lara. "La clasificación y la catalogación de las bibliotecas públicas de Nueva York", en El libro y el pueblo, II, 4-5 (junio-julio, 1923), p. 127.

32 Manrique de Lara. "La organización de bibliotecas públicas en la ciudad de Nueva York", en El libro y el pueblo, II, 6-7 (agosto-septiembre, 1923), pp. 171-172.

33 Manrique de Lara. "Programa de la Escuela de Bibliotecarios anexa a la Biblioteca Pública de Nueva York", en El libro y el pueblo, II, 8-10 (octubre-diciembre, 1923), pp. 201-202.

34 Manrique de Lara. "Bibliotecas y bibliotecarios",..., p. 33.

35 Manrique de Lara. "Anotaciones y revistas de libros", en El libro y el pueblo, III, 4-6 (abril-junio, 1924), pp. 89-92.

36 Manrique de Lara. "Informe y sugestiones que rinde la señorita Juana Manrique de Lara al Jefe del Departamento de Bibliotecas, como resultado de sus estudios especiales de biblioteconomía en la ciudad de Nueva York”, en El libro y el pueblo, III, 7-9 (julio-septiembre, 1924), pp. 172-173.

37 Manrique de Lara. "Proyectos de reformas e introducción ..., pp. 173-175.

38 Manrique de Lara. "Plan de un Boletín para una biblioteca de la ciudad de México", en Boletín de la Asociación de Bibliotecarios t I, 1 (15 de octubre, 1924), pp.5-6.

39 Manrique de Lara. "La selección de libros para las diferentes clases de bibliotecas y en especial para las bibliotecas públicas", en El libro y el pueblo, III, 10-12 (octubre- diciembre, 1924), pp. 227-229. 
Es necesario señalar que toda vez que estas propuestas coinciden con el fin del periodo vasconcelista, la atención de esta administración ya no era posible aun cuando algunas de ellas hubiesen sido consideradas como valiosas. No obstante ello con el tiempo algunas se fueron logrando pese a que otras están aún sin realizarse. Por otra parte hay que señalar que tanto la socialización de las ideas como el desconocimiento en nuestro medio de lo propuesto por Manrique de Lara en aquellos años, no permite que los bibliotecarios de la actualidad reconozcan que tiempo atrás, y muy oportunamente, esta autora ya lo hubiera sugerido.

\section{Aportaciones}

En conjunto los planteamientos, ideas, proyectos y artículos ofrecidos por Manrique de Lara desde Nueva York tocaron todos los aspectos que eran necesarios para desarrollar un verdadero sistema bibliotecario; así, bajo un nuevo concepto de biblioteca y de bibliotecario, proponía la adopción, "con las indispensables adaptaciones a nuestras especiales circunstancias", 40 de lo que ella denominaba

[...]los sistemas americanos de biblioteconomía [por ser ] los mejores del mundo, [...] [probado], con los espléndidos resultados que en el orden de un servicio público eficientísimo y rápido han alcanzado las bibliotecas de este país, en seguida con el hecho de que a sus escuelas de bibliotecarios vienen actualmente alumnos de todo el mundo a aprender dichos sistemas, $\left[\ldots . .{ }^{41}\right.$

Reconocía que para atender el

[...]mejoramiento general de las condiciones presentes del trabajo de bibliotecas [...] el primero e indispensable paso que es necesario dar [...] es el de continuar y reforzar con clases nuevas las conferencias de biblioteconomía que hasta ahora dirige el señor Juan B. Iguíniz [...], ${ }^{42}$

aunque consideraba la necesidad de fundar en "el futuro una Escuela de Bibliotecarios". 43 De esta forma encontramos que ubicaba como proyecto central la formación de los bibliotecarios.

40 Manrique de Lara, "Proyectos de reformas e introducción...”, p.174.

41 Ibid., 174.

42 Ibid., 174.

43 Manrique de Lara, “Programa de la Escuela ...”, pp. 201-202. 
Las aportaciones de Juana Manrique de Lara fueron las siguientes:

1. Manifestó la idea del papel central que tienen la biblioteca y el bibliotecario en la democratización del libro y la información. Si bien el término democratización no fue usado por Manrique de Lara, éste subyace en su artículo "Bibliotecas y bibliotecarios" ${ }^{\text {"44 }}$ y se aprecia como el núcleo de anclaje de la política bibliotecaria de México que también intenta emular a los Estados Unidos.

2. Definió a la biblioteca en contraposición al

[...]antiguo y errado concepto, [...] que las consideraba como un simple hacinamiento de libros más o menos arreglados, y cuyos preciosos volúmenes llegaban a manos de los escasísimos solicitantes después de infinidad de requisitos y cortapisas.

Así señaló:

En nuestra época las bibliotecas a las que antes se podía comparar a pozos de ciencia, son ahora canales que la llevan a dondequiera para fertilizar los entendimientos humanos en todas partes y en el mayor número posible. Se ha principiado [...] por instalarlas en edificios atractivos y limpios, de fácil acceso y acondicionados higiénicamente para mayor comodidad de sus visitantes. En seguida el acervo se ha escogido de la mejor manera posible, según las necesidades de la región, el grado de intelectualidad de los lectores y los diferentes fines para que han sido establecidas. Estos libros deben arreglarse por supuesto conforme a las reglas técnicas de la biblioteconomía, clasificándolas y ofreciendo al público catálogos de fácil consulta. Todo esto, y poniendo al frente a un bibliotecario competente, es lo que actualmente constituye la biblioteca ideal. [Complementa este idea señalando] Una biblioteca, además, debe ser un centro eficiente y gratuito de información tanto bibliográfica como general y estar siempre en aptitud de contestar a toda clase de preguntas que el público le haga. ${ }^{45}$

3. Ubicó al bibliotecario como el centro de la biblioteca, al señalar:

A pesar de todas las ventajas de una buena organización material en las bibliotecas, puede decirse que el éxito o fracaso de ellas depende casi por completo del bibliotecario que posea. En los tiempos modernos, el bibliotecario 
es un profesionista que necesita hacer estudios técnicos, serios, sobre su profesión y no un simple 'guardador y mozo de libros' como hasta hace poco tiempo se creía que fuera. Aparte de eso, se le exige ante todo una buena y extensa cultura general, espíritu de cortesía y de servicio, imaginación práctica y entusiasmo por su trabajo. ${ }^{46}$

Agregó:

Un bibliotecario ideal deberá tener entusiasmo por su trabajo y, en consecuencia, una imaginación práctica que le sugiera métodos, reformas y en general toda clase de ideas que realizadas en la práctica, contribuyan al mejoramiento, en todos sentidos, de la institución a su cargo, no perdiendo de vista, ante todo, el ideal de acercar el lector al libro, lo más posible, ${ }^{47}$

y también que:

Un buen bibliotecario deberá tener amor por los libros; pero no con la particular afición de un bibliómano o de un bibliófilo que guste de los libros por sus particularidades externas o circunstanciales, ya sea por su magnifica impresión, sus pastas o su rareza, sino que deberá amarlos por lo que en sí valen como receptáculos, que conservan para siempre el fruto de los cerebros privilegiados. Este amor por los libros en tal forma, lo conducirá a leer mucho, cosa indispensable para un bibliotecario, guía de otros en la cultura, y cuya instrucción y educación intelectual constituyen la base de su profesión. Esto mismo le servirá grandemente en su labor de información que es una de sus importantes funciones. ${ }^{48}$

Otra de las principales cualidades que deberá poseer es el espíritu de cortesía y de servicio en beneficio del público que acuda a su biblioteca. Se dice que es preferible que una biblioteca este técnicamente mal arreglada, pero que tenga un bibliotecario amable y bien dispuesto a ayudar al público en la busca de libros, que una cuya organización sea irreprochable, pero cuyo bibliotecario malhumorado y áspero ahuyente a los lectores. ${ }^{49}$

En cuanto a la necesaria experiencia que deberían tener los bibliotecarios encargados de bibliotecas especiales indicó

46 Manrique de Lara. “Bibliotecas y bibliotecarios”, p. 35.

47 Ibid., p. 35

48 Ibid., p. 35.

49 Ibid., p. 35. 
[...] es natural exigirles que sean titulados en su profesión, agregando a esto la técnica de bibliotecas. Así un bibliotecario de medicina, deberá ser un médico con entrenamiento especial de biblioteconomía. ${ }^{50}$

Respecto del perfil que debía reunir el bibliotecario de bibliotecas populares Manrique de Lara comentó lo siguiente:

En las bibliotecas populares, el bibliotecario tiene un amplio campo de trabajo y frecuentemente se convertirá en un profesor y en trabajador social. Su principal y más importante función consistirá, ante todo, en poner en contacto al lector con el libro que necesite. Hay que fijarse en que no digo con el libro que desee, sino con el libro que necesite, pues una de sus principales preocupaciones será poner en manos del solicitante, no el libro que pida, sino el que deba leer, aunque por su puesto, su buen sentido podrá indicarle las excepciones que deberán hacerse a esa regla. Después de esto, es su obligación que ese contacto entre el libro y el lector, sea de la manera más sencilla, fácil y cómoda, aun olvidándose de los reglamentos y teniendo, ante todo, la idea de que los libros están en la biblioteca para que el público los lea y que se debe fomentar a toda costa el amor y la facilidad para su lectura. No hay que olvidar en esta cuestión, que la reglamentación y método son necesarios para el orden de la biblioteca; pero nunca deberán ser éstos un obstáculo para que el lector se acerque con libertad al libro que necesite. ${ }^{51}$

4. Sugirió, respecto del proyecto medular para el funcionamiento del sistema bibliotecario, relacionado con la formación integral del bibliotecario, algunas ideas para atender también la formación de los bibliotecarios del interior del país. Al respecto, Manrique de Lara señalaba:

También como una rama dependiente de esta Escuela de Bibliotecarios se podría instituir un Departamento Consultivo de Biblioteconomía enteramente gratis para el público en general, y obligatorio para los bibliotecarios de la República para los cuales vendría a ser como una especie de curso de biblioteconomía por correspondencia, que, aunque siendo más elemental que el dado a los bibliotecarios de la ciudad de México les ayudaría a resolver muchos de los problemas que se presentan en las bibliotecas más pequeñas, contribuyéndose así a su mejor servicio. ${ }^{52}$ 
5. Propuso que la formación del bibliotecario estuviera encauzada a hacer posible que la biblioteca cumpliera su papel fundamental en la democratización del libro, la información y el uso de la propia biblioteca.

6. Expresó, respecto de los "estudios técnicos en biblioteconomía", punto central de la formación de los bibliotecarios, un concepto más amplio, más integral, que trascendía la idea de remitirlos únicamente a la catalogación y la clasificación, incluía también las materias de selección, administración, encabezamientos de materia y conocimientos acerca del servicio de consulta. Consideraba además que la formación del bibliotecario debía acompañarse de conocimientos que le permitieran acceder a una necesaria cultura general, por lo que sugería que esta formación se acompañara de una "elemental información sobre sucesos mundiales y domésticos”. Para apoyar este tipo de formación recomendó

traducir y adaptar los textos correspondientes a [los] usados en los Estados Unidos, y que son considerados como los mejores en las diferentes materias. Al mismo tiempo [sugirió que] se podrían hacer ediciones abreviadas de ellos, para su uso en bibliotecas pequeñas, cuyas especiales circunstancias bacen menores sus problemas. ${ }^{53}$

7. Fundamentó también la importancia de hacer una adecuada selección, misma que recomendaba enfrentar, como en Estados Unidos; esto es, “[...] según las necesidades de la región, el grado de intelectualidad de sus lectores y los diferentes fines para que han sido establecidas [las bibliotecas]" 54

8. Sugirió la adquisición y la selección centralizada, necesidad que fue planteada y justificada por ella en los siguientes términos:

Pasando a las actividades puramente técnicas, sugiero antes que otra cosa, que se establezca una sección de compra y selección de libros dependiente de ese Departamento, [se refería al Departamento de Bibliotecas de la SEP] la cual se encargaría de evaluar conforme a reglas definidas, tanto en el sentido material, como en su valor intrínseco y literario el material bibliográfico que el Departamento adquiera [...]. Este servicio redundará en incalculables beneficios tanto mejorando la calidad de la lectura que el público encontrará en las bibliotecas, como ahorrando al Departamento buenas sumas de dinero al cotejar los diferentes precios ofrecidos por las librerías [...]. ${ }^{55}$

53 Ibid.

54 Manrique de Lara, "Bibliotecas y bibliotecarios", pp. 33

55 Manrique de Lara, "Proyectos de reformas e introducción”, p.174. 
9. Recomendó la formación de un comité de selección dependiente del Departamento de Bibliotecas. Cabe acotar que ya desde entonces señaló la importancia de que el bibliotecario formara parte del comité de selección, por lo cual indicó: "Por supuesto que de esta comisión no podría ser excluido en materia alguna el bibliotecario para cuya biblioteca fueran comprados los libros [...]." ${ }^{\text {} 6}$

10. Propuso la catalogación y la clasificación centralizada. A este respecto, y seguramente en función de la falta de preparación de los bibliotecarios para realizar estos procesos a pesar de que el Departamento de Bibliotecas les impartía conferencias sobre estos temas, señaló:

\begin{abstract}
Se hace también muy necesario [...] el establecimiento de una Sección Central de Catalogación, en el cual se imitara hasta donde sea posible a la Biblioteca del Congreso de Washington [...]. Para esto se necesitará, ante todo, la unificación de sistemas de catalogación conforme a las reglas americanas". [También indicó que un] "[...] auxiliar importantísimo para la mejor realización de este proyecto serían las actividades bibliográficas que con material en lengua española se hagan, o se hayan hecho [...] [y que los trabajos en este sentido] podrían extenderse también a la literatura periódica, [...] a los documentos gubernamentales que contuvieran material útil para el público, y al material efímero, [con lo] cual se podrían organizar exhibiciones artísticas, históricas, etc., y se podrían formar para más tarde colecciones especiales en el tópico en que la biblioteca quisiera especializarse. ${ }^{57}$
\end{abstract}

11. Deseaba que en las campañas de difusión de las bibliotecas se usuran "[...]los diferentes métodos modernos de anuncio y publicidad que han dado resultados tan satisfactorios en otras líneas de actividades" ${ }^{58} \mathrm{Y}$ recomendó que cada biblioteca difundiera sus colecciones como forma de orientar hacia la lectura. Para ello proponía que la ficha del libro se acompañara de una anotación "descriptiva y no crítica". "Para formar al bibliotecario en la redacción de anotaciones escribió el artículo "Anotaciones y revistas de libros" ${ }^{60}$ en el que indicaba la importancia de esta actividad:

Una de las tareas bibliográficas más importantes, cuya utilidad es muy variada y de grande ayuda para los bibliotecarios y al mismo tiempo para

56 Manrique de Lara, "La selección de libros", pp. 227-229.

57 Manrique de Lara, "Proyectos de reformas e introducción”, pp.174-175.

58 Ibid., p. 174.

59 Manrique de Lara, "Plan de un boletín", p. 6.

8260 Manrique de Lara,"Anotaciones y revistas de libros”, pp. 89-92. 
el público en general, es la anotación y revistas de libros. Todo moderno bibliotecario está obligado a conocer hasta en sus menores detalles, el arte de la anotación bibliográfica y también el de hacer revistas de libros [...]. ${ }^{61}$

Para orientar a los bibliotecarios en la elaboración del boletín de difusión de su propia biblioteca publicó el articulo "Plan de un boletín para una Biblioteca de la Ciudad de México". ${ }^{62}$

12. Propugnó por el establecimiento de leyes especiales para las bibliotecas. Con relación a ello comentó:

Es tiempo ya de iniciar el establecimiento de leyes especiales que protejan el trabajo de las bibliotecas, para lo cual se estudiarán las circunstancia que le rodearon, así como aquellas leyes que puedan traerle positivas ventajas. ${ }^{63}$

13. Sostuvo, en cuanto a la búsqueda de ayuda privada para el sostenimiento de las bibliotecas:

[...] y si el público lograra interesarse en el trabajo que se está llevando a cabo, con el objeto de beneficiarlo a él mismo; tal vez podríamos alcanzar que la ayuda privada relevara, siquiera sea en parte, al gobierno de una carga de por sí bien pesada, siendo esto, si se lograra, un triunfo de educación cívica para los ciudadanos en general. ${ }^{64}$

14. Escribió desde Nueva York artículos de alto contenido académico que ubicamos como verdaderas lecciones para que los bibliotecarios comprendieran y contribuyeran a que la biblioteca desempeñara su papel tanto en el desarrollo del gusto lector como en la democratización del libro, la información y el uso de la propia biblioteca; entre tales artículos figuran: "Bibliotecas y bibliotecarios", "Anotaciones y revistas de libros" y "La selección de libros para las diferentes clases de bibliotecas y en especial para las bibliotecas públicas". La continuación de este artículo se publicó a principios de 1925 bajo el título "Selección de libros para las bibliotecas públicas". Estos fueron algunos de los primeros artículos que sobre estos temas se difundieron entre los bibliotecarios mexicanos del México posrevolucionario.

61 Ibid., p.89.

62 Manrique de Lara, "Plan de un boletín", pp. 5-6.

63 Manrique de Lara, "Proyectos de reformas e introducción”, p. 175.

64 Ibid., p. 175. 


\section{Acciones}

El fin del periodo de Vasconcelos (precipitado por enfrentamientos políticos y contrarios a la acción bibliotecaria de este personaje), el cambio que en esta política marcaba la presidencia de Álvaro Obregón y la reducción presupuestal hicieron que ni el propio Jefe del Departamento de Bibliotecas, Jaime Torres Bodet, quien valoraba las aportaciones de Manrique de Lara, pudiera hacer algo más que reconocer, apoyar y darle la oportunidad a Juana -a su regreso de Estados Unidos- de poner en práctica y transmitirles a otros bibliotecarios algunas de sus ideas. Ello se hacía posible al concederle el nombrarmiento de inspectora de algunas bibliotecas de la capital y al posibilitar que ella tomara parte en algunas acciones de importancia en el medio bibliotecario.

Así, en este apartado se refieren las actividades que Manrique de Lara pudo efectuar gracias a las oportunidades que Torres Bodet le brindara a su regreso de Estados Unidos. No obstante también relacionaremos algunas de sus propuestas con otros tiempos en que otros personajes o instituciones se ocuparon de ellas, sin que seguramente quienes las tomaron tuvieran conciencia de que esas propuestas habían sido presentadas por Manrique de Lara desde los años 20 del siglo pasado.

Las oportunidades que otros dieron a Manrique de Lara a su regreso de Estados Unidos y que nos indican el reconocimiento que se le otorgaba, fueron:

1. La primera acción que indica la importancia que Torres Bodet les dio a los escritos enviados por Manrique de Lara desde Estados Unidos fue la publicación de éstos en el órgano oficial del Departamento de Bibliotecas El Libro y el Pueblo que, como ya también hemos indicado, al ser distribuida internacionalmente dio la oportunidad de que la producción de Manrique de Lara pudiera ser conocida internacionalmente.

2. El nombramiento de Manrique de Lara como inspectora de bibliotecas.

3. Su incorporación a la Asociación de Bibliotecarios Mexicanos participando en su Junta Directiva.

4. La organización de la biblioteca del general Álvaro Obregón, entonces presidente de la República.

5. La reorganización de las grandes y principales bibliotecas del país, tales como la Biblioteca "Modelo" de la SEP y la "Iberoamericana".

Por su parte Manrique de Lara, desde su lugar de inspectora de bibliotecas, realizó las siguientes acciones:

6. La elaboración de nuevos y más prácticos formatos de préstamo y de estadísticas en las bibliotecas. 
7. La formulación de una lista de obras para niños con miras a que sirviera como instrumento de selección.

8. La capacitación del personal de las bibliotecas que inspeccionaba para llevar a efecto la catalogación y clasificación de éstas.

9. La traducción hasta dos cifras de la clasificación de Melvil Dewey para la clasificación de bibliotecas.

10. La realización de campañas de publicidad para las bibliotecas entre las comunidades a las que servían.

11. La difusión de listados anotados de las obras que poseía individualmente cada biblioteca.

12. Las exposiciones temáticas de los libros que se encontraban en cada biblioteca.

13. La elaboración de artículos para publicación tal como el de "Anotación y revistas bibliográficas”.

14. El inicio de publicaciones dirigidas a la organización de las pequeñas bibliotecas.

15. Su participación como ponente en la primera Feria del Libro, como única conferencista mujer, con el tema: "La labor de la Secretaría de Educación en el ramo de bibliotecas populares".

16. Su conferencia ante bibliotecarios mexicanos con el fin de que éstos ampliaran su panorama con el conocimiento de las bibliotecas de los Estados Unidos.

Su proyecto para conformar una escuela para bibliotecarios con una visión integral de formación fue una de las propuestas que por ser medular fue atendida si no durante el periodo de Vasconcelos, sí en 1925 por la nueva Jefa del Departamento de Bibliotecas Esperanza Velázquez Bringas. Esta idea fue apoyada también en ese momento por la recién fundada Asociación de Bibliotecarios Mexicanos. Años más tarde, cuando Jaime Torres Bodet se convirtió en Secretario de Educación Pública durante el periodo 1943-1946, fundó la escuela de bibliotecarios de la SEP que perdura hasta nuestros días. Entendemos que si hubiera estado en manos de Torres Bodet el hecho de dar curso al planteamiento que hiciera Manrique de Lara en correspondencia con esa acción entre 1923 y1924, lo hubiese realizado.

Cabe señalar como otra aportación que debido a la participación de Juana tanto en el diseño de los planes de estudios de la escuela de 1925 y de 1945 como en la impartición de materias que:

Los contenidos académicos propuestos por Manrique de Lara y también por la comunidad bibliotecaria permearon los planes de estudio de las escuelas de biblioteconomía y bibliotecología que se abrieron en México durante el siglo XX. 
Desafortunadamente otras propuestas importantes para el funcionamiento de las bibliotecas públicas como fueron las de catalogación y clasificación centralizadas, se empezaron a trabajar en la SEP hasta 1978 con la creación de la Dirección General de Publicaciones y Bibliotecas. ${ }^{65}$ En cuanto a las leyes para bibliotecarios encontramos que no fue sino hasta 1944, cuando Jorge Duran González, durante el tercer Congreso Nacional de Bibliotecarios, presentó el "Proyecto de Ley del Servicio Nacional Bibliotecario". ${ }^{66}$ Sin embargo fue solo en 1988 cuando se promulgó la Ley General de Bibliotecas. Esta Ley en realidad define la Red Nacional de Bibliotecas Públicas y sus objetivos, propone medios para propiciar la prestación idónea de este servicio y crea el Consejo Red Nacional de Bibliotecas Públicas.

Asimismo la ley declara el interés social por integrar un sistema Nacional de Bibliotecas en el que participen voluntariamente las bibliotecas escolares, públicas, universitarias y especializadas de todos los sectores. ${ }^{67}$

\section{Influencias}

El marco referencial del que parten las propuestas realizadas por Manrique de Lara entre 1923 y 1924 es indudablemente el desarrollo bibliotecario logrado en los Estados Unidos y particularmente en Nueva York.

La formación de bibliotecarios como proyecto central para mejorar el sistema bibliotecario nos muestra que para Manrique de Lara — de igual manera que para Melvil Dewey y para los intelectuales del régimen de Carranza, en especial para Loera y Chávez-, el proyecto se constituía en acción fundamental para un desarrollo bibliotecario que conceptualizaba a la biblioteca moderna como la institución social por excelencia que podía democratizar el libro, la lectura y la información, y constituirlos en una apoyo fundamental no sólo para la vida educativa sino también para el desarrollo cultural y el progreso de la comunidad.

Al finalizar la presente investigación encontramos que Juana Manrique de Lara Macías hizo propuestas fundamentales no únicamente para el periodo bibliotecario inspirado por Vasconcelos, quien buscaba alcanzar la democratización del libro y la biblioteca, sino que algunas de ellas al ser importantes y no haberse aplicado sistemáticamente trascienden ese momento y son,

65 Edgar López RobledoRoblero, "Centralización de los procesos teóricos en la Dirección General de Publicaciones y Bibliotecas de la SEP”, en Servicio de la Bibliotecología (4ª) Guadalajara, Jal. Universidad Autónoma de Guadalajara/Dirección de Bibliotecas, 1982, pp. 151-158.

66 Memoria del Tercer Congreso Nacional de Bibliotecarios y primero de Archivistas. México, D.F., H. Congreso de los Estados Unidos Mexicanos/sEP, 1944, pp. 488-492.

67 Cfr. México, Leyes, decretos, etcétera, Ley general General de Bibliotecas Públicas: texto y debate parlamentario, México, SEP, Dirección General de Bibliotecas, 1988, 69p. 
en lo esencial, vigentes aún para el desarrollo bibliotecario y la conformación de una sociedad lectora en el México del siglo XXI.

\title{
DOCUMENTOS DE ARCHIVOS CONSUlTAdOS
}

Siglas empleadas:

\author{
AHBN: Archivo Histórico de la Biblioteca Nacional \\ AHBN, Fondo Administrativo.
}

\section{Carpeta 70.}

Exp. 1558. No. 2515. [Oficio turnado por Agustín Loera y Chávez, Subdirector de la Biblioteca Nacional, al Subsecretario de Instrucción Pública y Bellas Artes, 21 de Septiembre de 1915].

Exp. 1559. No. 2516. [Decreto de institución de bibliotecas infantiles en las Escuelas Primarias Superiores. 20 de noviembre de 1915].

\section{Carpeta 77.}

Exp. 1908. No. 2870. [Relación de oficios emitidos por la Biblioteca Nacional durante el año de 1917].

AHBN, Fondo de la Escuela Nacional de Bibliotecarios y Archivistas

\section{Carpeta 114.}

Exp. 3360. No. 4354. [Sugerencia del Director de la Escuela Nacional de Bibliotecarios y Archivistas al Ministro de Educación, de incluir en los programas de Lengua Nacional el tema de manejo de bibliotecas y uso, selección y prácticas de asimilación de libros. 20 de abril de 1916].

\section{OBRAS CONSULTADAS}

"Informe rendido por la inspección del Departamento de Bibliotecas acerca del funcionamiento de las bibliotecas públicas fundadas en la ciudad de México y en algunas poblaciones del Distrito Federal", en Boletín de la Secretaría de Educación Pública, I, 3 (enero, 1923), pp. 323-325. 
"La biblioteca infantil", en El libro y el pueblo, II, 8-10 (octubrediciembre, 1923), p. 202.

"Las Bibliotecas Públicas en México", en El libro y el pueblo, II, 6-7 (agosto-septiembre, 1923), pp. 137-139.

Lecturas clásicas para niños. México, D.F., SEP. Departamento Editorial, 1981, 2 vols.

León Calderón, Nicolás. Biblioteconomía: notas de las lecciones orales del Profesor Dr. Nicolás León en la Escuela Nacional de Bibliotecarios y Archiveros. México, D.F., Antigua Imprenta de Murguía, 1918, vii, 167 p.

Ley General de Bibliotecas, en Diario Oficial de la Federación, tomo CDXII, No. 14. México, D. F., jueves 21 de enero de 1988.

Loera y Chávez, Agustín. "Inauguración de la Escuela de Bibliotecarios y Archiveros", en Boletín de la Biblioteca Nacional de México, II, 4 (octubre, 1916), pp. 146-149.

López Roblero, Edgar, "Centralización de los procesos técnicos en la Dirección General de Publicaciones y Bibliotecas de la Secretaría de Educación Pública”, en Cooperación bibliotecaria: estado actual y perspectivas. Memorias IV Semana de Bibliotecología del 29 de septiembre al 4 de octubre de 1980. Guadalajara, Jal., Universidad Autónoma de Guadalajara. Dirección de Bibliotecas, 1982, pp. 151-158.

Manrique de Lara, Juana, “Anotaciones y revistas de libros”, en El libro y el pueblo, III, 4-6 (abril-junio, 1924), pp. 89-92.

_, "La Biblioteca Pública de Nueva York: Informe al Departamento de Bibliotecas", en El libro y el pueblo, II, 2-3 (abrilmayo, 1923), p. 35.

"La biblioteca pública y los alumnos de las escuelas preparatorias", en Biblos, III, 145 (29 octubre, 1921), p. 175. "Bibliotecas infantiles y juveniles", en Biblos, IV, 158, 159 (28 enero, 4 febrero, 1922), pp. 15, 18-19.

, "Las bibliotecas públicas y los alumnos de las escuelas primarias", en Biblos, III, 146 (5 noviembre, 1921), p. 179. , "Bibliotecas y bibliotecarios", en El libro y el pueblo, III, 3 (enero-marzo, 1924), p. 33.

"La clasificación y la catalogación de las bibliotecas públicas de Nueva York”, en El libro y el pueblo, II, 4-5 (junio-julio, 1923), p. 127.

"Informe que la señorita Juana Manrique de Lara, oficial bibliotecario, presenta al ciudadano Jefe del Departamento de Bibliotecas, relativo a sus estudios en Estados Unidos: La Escuela de Bibliotecarios de la Biblioteca Pública de Nueva York y requisitos para ingresar a ella", en Boletín de la Secretaría de Educación Pública I, 4 (enero-junio, 1923), p. 298. 
, "Informe y sugestiones que rinde la señorita Juana Manrique de Lara al Jefe del Departamento de Bibliotecas, como resultado de sus estudios especiales de biblioteconomía en la ciudad de Nueva York", en El libro y el pueblo, III, 7-9 (julio-septiembre, 1924), pp. 172-173.

, "La organización de bibliotecas públicas en la ciudad de Nueva York", en El libro y el pueblo, II, 6-7 (agosto-septiembre, 1923), pp. 171-172. "Plan de un Boletín para una biblioteca de la ciudad de México", en Boletín de la Asociación de Bibliotecarios t I, 1 (15 de octubre, 1924), pp.5-6.

, "Programa de la Escuela de Bibliotecarios anexa a la Biblioteca Pública de Nueva York", en El libro y el pueblo, II, 8-10 (octubre-diciembre, 1923), pp. 201-202.

"Proyecto de reglamento interior para uso de la biblioteca Amado Nervo”, en El libro y el pueblo, I, 12 (febrero, 1923), p. 203.

"Proyectos de reformas e introducción de sistemas de biblioteconomía, según los métodos norteamericanos, en las bibliotecas de la República Mexicana”, en El libro y el pueblo, III, 7-9 (julio-septiembre, 1924), pp. 173-175.

"La selección de libros para las diferentes clases de bibliotecas y en especial para las bibliotecas públicas", en El libro y el pueblo, III, 10-12 (octubre- diciembre, 1924), pp. 227-229.

Memoria del Tercer Congreso Nacional de Bibliotecarios y primero de Archivistas, México, D. F., H. Congreso de los Estados Unidos Mexicanos / SEP, 1944, pp. 488-492.

México. Leyes, decretos, etc., Ley general de bibliotecas públicas: texto y debate parlamentario. México, D. F., Secretaría de Educación Pública. Dirección General de Bibliotecas, 1988, 69 p.

Morales Campos, Estela M., "Entrevista: Juana Manrique de Lara”, en Investigación bibliotecológica: archivonomía, bibliotecología e información, I, 1 (agosto, 1986), pp. 8-23.

"Reglamento de la Secretaría de Educación Pública Federal, en Boletín de la Secretaría de Educación Pública", I, 2 (septiembre, 1922), pp. 32-75.

"Reglamento de las bibliotecas públicas", en El libro y el pueblo, I, 4 (junio, 1922), p. 26. Al calce: J. Vasconcelos. El Secretario de Educación Pública.

Sametz de Walerstein, Linda, Vasconcelos el hombre del libro: la época de oro de las bibliotecas, México, D.F., Instituto de Investigaciones Bibliográficas, UNAM, 1991, 227 p.

“Tipos de bibliotecas", en Boletín de la Secretaría de Educación Pública, I, 1, (1'. Mayo, 1922, pp. 295-298. 


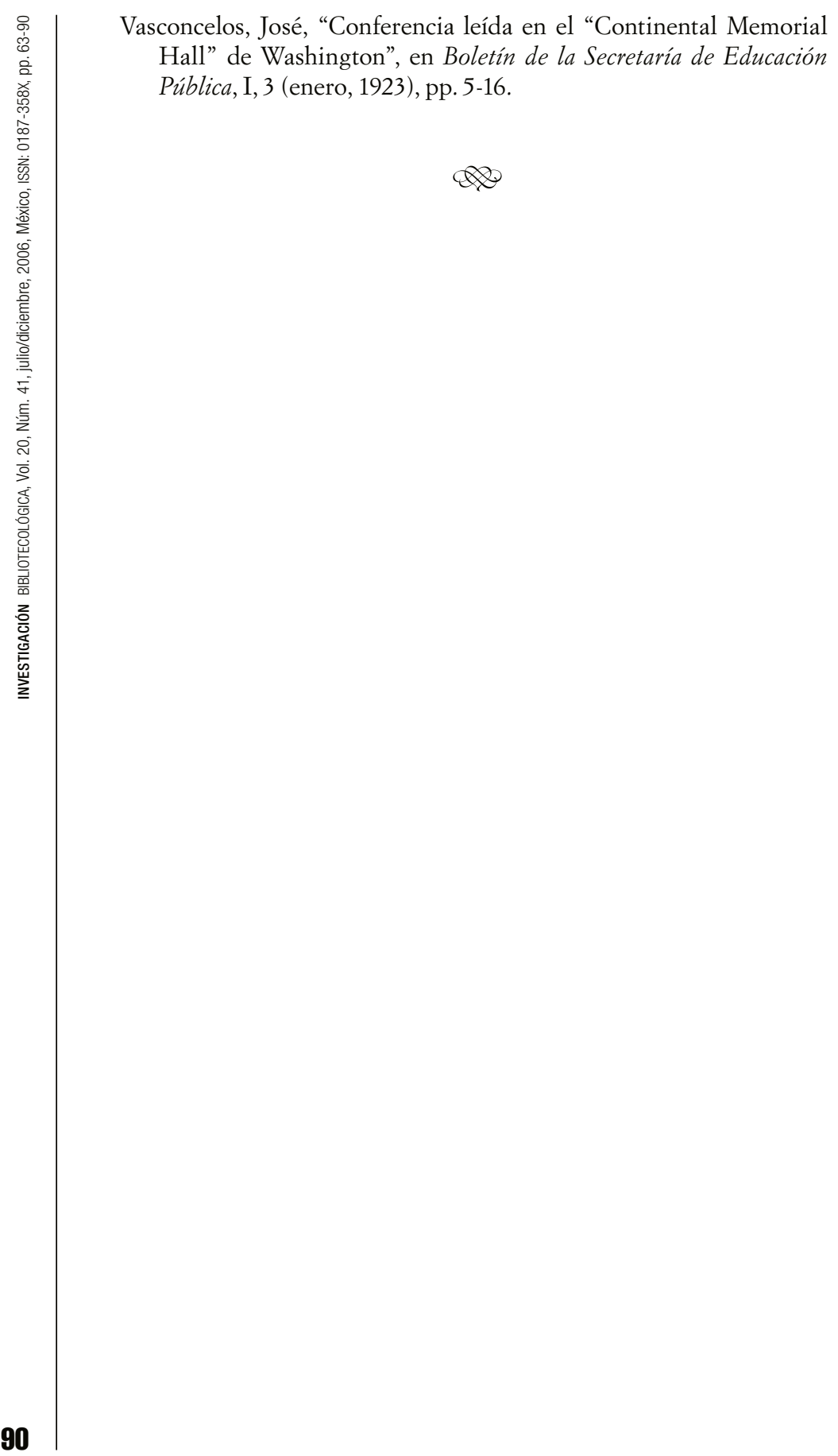

